\title{
Peertechz
}
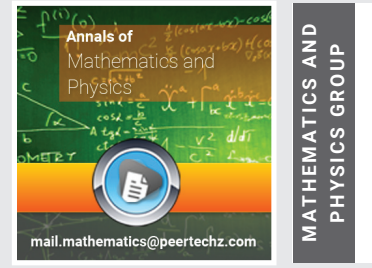

\section{On freedman equation and the shape of our universe}

\section{S Kalimuthu*}

2/394, Kanjampatti P.O, Pollachi, Tamil Nadu 642003, India

Received: 01 June, 2020

Accepted: 16 July, 2020

Published: 17 July, 2020

*Corresponding author: S Kalimuthu, 2/394,

Kanjampatti P.O, Pollachi, Tamil Nadu 642003, India, Tel: +91 8220541577;

E-mail: owlskalimuthu@gmail.com

Keywords: Freedman Equations; Application of algebra; The shape of our universe

https://www.peertechz.com

\section{Abstract}

In the nineteen twenties, the famous Russian mathematician Alexander Freedman formulated an equation which determines the shape and fate of our universe. Freedman derived his equation in general relativity. The equation reveals that the geometry of the universe may be flat, closed or open. The Euclidean, hyperbolic and spherical geometries describe the flat, open and closed universes respectively. Both NASA's WMAP and ESA's PLANCK mission show the cosmological curvature parameter, $\Omega_{k}$, to be $0.000 \pm 0.005$, consistent with a flat universe. Many observational cosmological probes revealed that the universe is flat obeying the classical Euclidean geometry. But till this day, there is no mathematical formulation/proof for the geometry of our universe. In this work, the attempts to establish that the shape of our universe is flat.

\section{Proof one}

The density parameter $\Omega$, the curvature parameter $\mathrm{k}$ and the Hubble parameter $\mathrm{H}$ are related as [1-5].

$$
(1-\Omega)=-\mathrm{kc}^{2} / \mathrm{H}^{2} \mathrm{R}^{2}
$$

If omega less than $1, \mathrm{k}$ is less than 1

If omega is equal to $1, \mathrm{k}$ is zero

If omega greater than $1, \mathrm{k}$ is +1 .

If $\mathrm{k}$ is -1 , the geometry of the universe is open,

If it is greater than one, the shape of the universe is closed

And the universe obeys Euclidean geometry if $\mathrm{k}$ is equal to zero.

I.e if $\Omega=1$, the universe is Euclidean,

If $\Omega=$ less than 1 , the geometry of the universe is open,

And if $\Omega=$ greater than 1 , the universe is closed,

Let $-\mathrm{n}=-\mathrm{kc}^{2} / \mathrm{H}^{2} \mathrm{R}^{2}$ in (1)

Assuming (1a) in (2), $1-\Omega+n=0$

Squaring, $1+\Omega^{2}+n^{2}-2 \Omega-2 n \Omega-2 n=0$ i.e $(\Omega-n)^{2}=2 \Omega+2 n-1=0$

From (1a) we have, $\Omega-\mathrm{n}=1$. Putting this in the first factor of the above equation,

$=2 \Omega+2 n-1$

Simplifying, $1=\Omega+n$

But from eqn. (1a) ,1 $=\Omega-n$

Adding the above two relations, $1=\Omega(2)$

As we have previously seen in $\Omega$ is equal to 1 , the curvature of our universe is zero and the geometry of our universe is flat [6].

\section{Proof two}

The density parameter $\Omega$, the curvature parameter $\mathrm{k}$ and the Hubble parameter $\mathrm{H}$ are related as $[7,8]$

$(1-\Omega)=-\mathrm{kc}^{2} / \mathrm{H}^{2} \mathrm{R}^{2}$

If omega less than $1, \mathrm{k}$ is less than 1

If omega is equal to $1, \mathrm{k}$ is zero

If omega greater than $1, \mathrm{k}$ is +1 . 
If $\mathrm{k}$ is -1 , the geometry of the universe is open,

If it is greater than one, the shape of the universe is closed

And the universe obeys Euclidean geometry if $\mathrm{k}$ is equal to zero.

I.e if $\Omega=1$, the universe is Euclidean,

If $\Omega=$ less than 1 , the geometry of the universe is open,

And if $\Omega=$ greater than 1 , the universe is closed.

For our convenience, let us assume in $(1),-n=-k^{2} / H^{2} R^{2}$

So, $(1-\Omega)=-\mathrm{n}$

Applying (1a) and cubing (1) we get that,

$1-\Omega^{3}-3 \Omega(1-\Omega)=-n^{3}$

i.e $\left(n^{3}-\Omega^{3)}+1-3 \Omega(1-\Omega)=0\right.$

By applying the famous algebraic cubic formula $a^{3}-b^{3}=$ $(a-b)^{3}+3 a b(a b)$ in the first factor of the above relation we obtain that,

$(n-\Omega)^{3}+3 n \Omega(n-\Omega)=-1+3 \Omega(1-\Omega)$

From (1a) we have, $\mathrm{n}-\Omega=-1$

Putting this relation in the above eqn. we have, $\mathrm{n}(\mathrm{n}-\Omega)$

$=\Omega(1-\Omega)$

Again applying (1a) in RHS, n $(n-\Omega)=-n \Omega$

From (1a) we also have, $n-\Omega=-1$

By assuming the above relation in the LHS of (2) we get - n $=-\mathrm{n} \Omega$

By simplifying we get that $\Omega=1$

\section{Discussion}

From equations (2)and (4) we can conclude that the geometry of our Universe is FLAT.

The shape of the entire relies on the following properties:

1. Finite or infinite

2. The geometry is flat, hyperbolic or elliptic

Simply connected space or multiply connected space

The exact shape is a burning problem in physical cosmology. Several experimental and observational data WMAP, PLANCK, BOOMERanG confirm that the universe is flat with only a $0.4 \%$ margin of error. Theorists believe that the universe is flat and infinite. Our finding adds more and more favorable arguments for the shape and fate of our universe.

\section{References}

1. Cornish NJ, Weeks RJ (2000) Measuring the shape of the Universe. Link: https://bit.ly/2ZyFbBI

2. Luminet JP (2006) The Shape and Topology of the Universe. 21. Link: https://bit.ly/2CD8xG9

3. Aurich R, Lustig S, Steiner F, Then H (2004) Can one hear the shape of the Universe? Phys Rev Lett 4. Link: https://bit.ly/3940k8a

4. Cornish N, Spergel D, Starkman G (1998) Can COBE see the shape of the universe?. Phys Rev 16. Link: https://bit.ly/3fIV5PS

5. Gomero GI (2002) Can We See the Shape of the Universe?. Int J Mod Phys 6 Link: https://bit.ly/3h56KbO

6. Gomero GI, Reboucas MJ, Teixeira AFF (2000) Signature for the Shape of the Universe. Int J Mod Phys 11. Link: https://bit.ly/3h7grGH

7. Gomero $\mathrm{GI}$ (2003) Determining the shape of the Universe using discrete sources. Class Quant Grav 11. Link: https://bit.ly/3eDUaif

8. Bayin SS (2013) Is the Universe Flat?. Link: https://bit.ly/3fDotH4
Discover a bigger Impact and Visibility of your article publication with

\section{Peertechz Publications}

\section{Highlights}

* Signatory publisher of ORCID

- Signatory Publisher of DORA (San Francisco Declaration on Research Assessment)

* Articles archived in worlds' renowned service providers such as Portico, CNKI, AGRIS, TDNet, Base (Bielefeld University Library), CrossRef, Scilit, J-Gate etc.

* Journals indexed in ICMJE, SHERPA/ROMEO, Google Scholar etc.

* OAI-PMH (Open Archives Initiative Protocol for Metadata Harvesting)

* Dedicated Editorial Board for every journa

* Accurate and rapid peer-review process

* Increased citations of published articles through promotions

* Reduced timeline for article publication

Submit your articles and experience a new surge in publication services (https://www.peertechz.com/submission).

Peertechz journals wishes everlasting success in your every endeavours.

Copyright: @ 2020 Kalimuthu S. This is an open-access article distributed under the terms of the Creative Commons Attribution License, which permits unrestricted use distribution, and reproduction in any medium, provided the original author and source are credited. 